\title{
Chemical Composition and Medicinal Values of Camel Milk
}

\author{
Kula Jilo ${ }^{1}$, Dechasa Tegegne ${ }^{2}$ \\ Jimma University, School of Veterinary Medicine \\ Jimma, Ethiopia \\ ${ }^{1}$ kula.jilo1@gmail.com
}

Jilo Kula, Dechasa Tegegne, Jimma university school of veterinary medicine: chemical composition and medicinal values of camel milk: Review.

\begin{abstract}
Out of 25.89 million camel populations on the world $89 \%$ are one-humped camels and the remaining $11 \%$ are the two-humped. More than $60 \%$ of the dromedary camel population is concentrated in the arid areas of North East African countries. Ethiopia ranks third by the number of camel population and second by camel milk production from the globe. Camel milk, white gold of the desert is more similar to human milk. It differs from other mammals milk as its chemical composition is low cholesterol, low sugar, high minerals, high vitamin $C$ and higher protective proteins like lactoferrin, lactoperoxidase, immunoglobulins and lysozyme, lacks B-lactoglobulin. $\beta$-lactoglobulin camel milk is unique in terms of antioxidative factors, antibacterial, antiviral, antifungal, anti-hepatitis, anti arthritis, treatment for paratuberculosis, preventies aging, remedy for autoimmune diseases and it has cosmetic values. Insulin in camel milk is safe and efficacious in improving longterm glycemic control in diabetic patient. Camel milk reduces autism symptoms in children. Lactoferrin has ability to inhibit the proliferation of cancer cell. Camel milk is rich in magnesium and zinc thus endowed antiulcer properties. Camel milk has high $\alpha$-hydroxyl acids which are known to plump and smoothies the skin and also used to treat skin disorders such as dermatitis, Acne, Psoriasis and Eczema. Although camel milk has such values, it's less appreciated thus its consumption is restricted to pastoral area so further studies should be conducted on the chemical composition and medicinal value of camel milk.
\end{abstract}

Keywords: camel milk, chemical composition, medicinal value

\section{INTRODUCTION}

As stimation of Food and Agriculture Organization (2013) the total population of camel in the world is believed to be 25.89 million, of which $89 \%$ are one-humped dromedary camels (Camelusdromedarius) and the remaining $11 \%$ are the two-humped (Camelusbactrianus) that generally found in the cold deserts of Asia while more than $60 \%$ of the dromedary camel population is concentrated in the arid areas of North East African countries like Somalia, Sudan, Ethiopia and Kenya.Ethiopia ranks third in the world by the number of camel herd after Somalia and Sudan (Simeneh et al.,2015).

For desert people in Asia and Africa, camel is vital to daily life as a source of food and a means of transportation, and just as importantly, its milk has been used as medicines for diverse ailments since ancient times(Gader et al.,2016). Camel can produce more milk for a longer period of time in arid zones and harshy environment than any other domestic livestock species(Ahmed et al., 2015).The daily yield of camel milk ranges from 3 to $10 \mathrm{~kg}$ in a lactation period of 12 to 18 months (Gizachew et al., 2014).Ethiopia which possesses about 2.4 million heads camels ranks second in camel milk production in the world next to Somalia. The annual camel milk production in Ethiopia is estimated as 75,000 tones (Asres and Yusuf, 2014).

Camel milk so called white gold of the desert is more similar to human milk than any other milk and differs from other ruminant milk because it contains low cholesterol, low sugar, high minerals (sodium, potassium, iron, copper, zinc and magnesium), high vitamin C,protective proteins like as lactoferrin, lactoperoxidase,immunoglobulins, lysozyme (Yadav et al., 2015). Camel milk has been acknowledged for a long time to provide a potential treatment for a series of diseases such as dropsy, jaundice, anti-hypertensive, asthma, and leishmaniasis or kala-azar. (Asresie et al., 2014 and Yardav et al., 2015). 
It has been reported that camel milk contains the low quantity of $\beta$-casein and the lack of $\beta$ lactoglobulin wich cause allergic reaction in lactose intolerant person (Konuspayeva et al., 2009). Nevertheless, it contains insulin-like and protective protein used for the treatment of many ailments like diabetes, autism, and diarrhea and possesses anti-tumors properties (Gul et al., 2015). Moreover, camel milk is endowed with very strong immune system (Grader et al., 2016) and remedy for peptic ulcers anti-malignant (Korashy et al., 2012) anti-platlet and anti-thrombotic properties (Abdelgadir et al., 2013). More recently, studies confirmed that camel's milk is unique in terms of antioxidative factors, antibacterial, antiviral, antifungal, anti-hepatitis, treatment for paratuberculosis, hypoglycaemic activity, anticancer, preventives of aging, remedy for autoimmune diseases, cosmetic and detergents (Al-Juboori et al., 2013, Sharma et al. ,2014, Keskes, 2015).

A numerous reviews have been carried out in different milking animals despite these all benefets chemical composition and medicinal values of camel milk was not reviewed which created information gap in the area.

Therefore in the line with the above, the objectives of this paper are:-

To review available information on chemical composition and medicinal values of camel milk.

To recommend further investigation concerning chemical composition and medicinal values of camel milk based on the information from this review.

\section{LiterATURE REVIEW}

\subsection{Chemical Composition of Camel Milk}

Camel's milk is generally an opaque white color and has a faint sweetish odor and sharp taste; some times it can be salty (Abbas, 2013). Its opaque white color because of the fats are finely homogenized throughout the milk where as, the changes in taste are caused by the type of fodder and availability of drinking water (Yadav et al., 2015). Its density ranges from 1.026-1.035 and the $\mathrm{pH}$ from 6.2-6.5, both are lower than those of the cow's milk and maximum buffering capacity of skim milk is at $\mathrm{pH}$ 4.95. (Gul et al., 2015)

According to most authors the composition of camel milk varies due to difference of geographical origin and year of publication of the published datas but other factors such as the physiological stage, feeding conditions, seasonal or physiological variations, genetic or health status of camel have also a paramount importance(Konuspayeva et.al., 2009). In genaral the average amount of components of camel milk is protein $3.4 \%$; fat $3.5 \%$; lactose $4.4 \%$; ash $0.79 \%$, while water covers $87 \%$ (Kanhal and Hamad, 2010).

Table1. Chemical composition of milk of different species

\begin{tabular}{|l|l|l|l|l|l|}
\hline Proximate & Water \% & Protein \% & Fat \% & Ash \% & Lactose \% \\
\hline Camel & $86-88$ & $3.0-3.9$ & $2.9-5.4$ & $0.6-0.9$ & 3.3 \\
\hline Cow & $85-87$ & $3.2-3.8$ & $3.7-4.4$ & $0.7-0.8$ & $4.8-4.9$ \\
\hline Buffalo & $82-84$ & $3.3-3.6$ & $7.0-11.5$ & $0.8-0.9$ & $4.5-5.0$ \\
\hline Sheep & $79-82$ & $5.6-6.7$ & $6.9-8.6$ & $0.9-0.1$ & $4.3-4.8$ \\
\hline Goat & $87-88$ & $2.9-3.7$ & $4.0-4.5$ & $0.8-0.9$ & $3.6-4.2$ \\
\hline Human & $88-89$ & $1.1-1.3$ & $3.3-4.7$ & $0.2-0.3$ & $6.8-7.0$ \\
\hline
\end{tabular}

Source: (Kanhal and Hamad, 2010)

\subsubsection{Proteins}

Milk proteins are a heterogeneous group of compounds that differ in composition and properties (Gizachew et al., 2014). Dromedary camel milk contains 3 to 3.90 percent of protein (table 1). It contains two main groups (Caseins and Whey proteins and relatively higher amount immune proteins (Peptidoglycan Recognition Protein, Lactoferrin Lysozyme and Lactoperoxidase) and insulin (Abbas et al., 2013, Gul et al., 2015).

Casein is the most important and higher in proportion, while the proportion of whey proteins is relatively low (Guo et al., 2007). Shamsia (2009) also comfirmed that camel milk contains higher protein (especially casein) and lower in whey milk than human milk.

Casein is a major part of protein in camel milk. Dromedary camel milk has 1.63 to 2.76 percent of casein protein that constitutes 52 to 87 percent of total milk protein (Khaskheli et al., 2005). There are 
4 main casein fractions casein: $\alpha s 1-, \alpha \mathrm{s} 2-, \beta$-, and $\kappa$. their proportion is diverse and polymorphism of these proteins was demonstrated in most of the animal species (Barłowska, 2007). The human casein does not contain the $\alpha$ s1-fraction, which is the predominant factor causing milk protein allergy. However; it is rich in the $\beta$-fraction. But casein in cow and buffalo milk is very abundant (38.4\% and $30.2 \%$ of total casein, respectively) in the $\alpha$ s 1 -fraction (Zicarelli, 2004). Milk protein allergy (MPA) is an allergic reaction to proteins commonly found in cow milk. In whole casein portion, $\beta-\mathrm{CN}$ is 65 percent and $\alpha \mathrm{s} 1-\mathrm{CN}$ is 21 percent. Camel milk has more digestibility and less allergic reactions in infants as $\alpha$ s-CN slowly hydrolyze than $\beta$-CN (El-Agamy et al., 2009).

Whey protein is the second biggest fraction of protein of camel milk which covers 20 to 25 percent of camel milk protein. The milk of dromedary camel has a whey protein in range of 0.63 and 0.80 percent (Khaskheli et al., 2005). B-lactoglobulin is found in trace, while $\alpha$-lactalbumin comprises the major camel milk portion. In the milk of bovines, $\alpha$-lactalbumin constitute only 25 percent, while $\beta$ lactoglobulin made 50 percent of the total whey protein that make it the major whey protein of bovine milk(Laleye et al., 2008). Whey protein of camel milk consists of some other main components such as peptidoglycan, recognition protein, immunoglobulins, lactoferrin and serum albumin (Kappeler et al., 2005)

Peptidoglycan Recognition Protein (PGRP); its highest concentration was first discovered in camel milk and it has apparent effect on breast cancer by controlling metastasis an stimulates the host's immune response (Gizachew et al., 2014). It stimulates the host's immune response and has potent antimicrobial activity. It even appears to have an effect on breast cancer in studies (Gul et al., 2015).

Lactoferrin is a glycoprotein which has an ability to bind two metal cations (preferably $\mathrm{Fe} 3+$ ) to the binding sites that are structurally closely related.The majority of lactoferrin is needed for transportation or storage of iron and posses antioxidant properties. . Lactoferrin contents of camel milk (0.22 mg.mL-1) were significantly higher than goat, sheep, buffalo and cow milk (Abas et al.,2013).The research of El-Hatmi(2007) revealed that highest level of lactoferrin(2.3 g.L-1) was noticed after 2 days of parturition. Lactoferrin is among the protective proteins in camel milk with higher concentration and thus prevents microbial overgrowth and invading pathogens (Hosam HM et al., 2013)

Lactoperoxidase is resistant to acidic and proteolytic digestion contributes to the non-immune host defense system, exerting bactericidal activity,growth promotion activity, anti-tumor activity and it has a close relation (71\%) to human thyroid peroxidase, which is involved in iodination and coupling in the formation of the thyroid hormones(Mullaicharam et al., 2014). Lactoperoxidase has bactericidal activity mainluy on gram-negative bacteria like Escherichia coli, Salmonella, and, Pseudomonas, (Abbas et al., 2013, Gul et al., 2015).

Lysozyme is a protective protein highest in camel milk than milk of cow and human. It has antibacterial activity gram-positive bacteria like N-acetyl-beta-D-glucosamidase (NAGase) found in similar quantities in human milk (Gul et al., 2015).

The immunoglobulins in camel milk contribute to camel milk's incredible infection fighting. Camel Igs are able to penetrate tissues and cells that human Igs were unable to. Because of their reduced size, one-tenth the size of human antibodies, thus can readily pass to the milk of the lactating camel, can pass the BBB, and readily absorbed from the gut into the general circulation (Gader, 2016). Additionally, the level of immunoglobulin $\mathrm{G}$ in camel milk is $1.64 \mathrm{mg} . \mathrm{mL}-1$ which is highest as compared to $0.70,0.67,0.55,0.63$ and $0.86 \mathrm{mg} . \mathrm{mL}-1$ for goat, cow, sheep, buffalo and human milk respectively (El-Agamy and Nawar, 2009).

\subsubsection{Fats}

The level of dromedary camel milk fat believed to be 2.9 to 5.4 percent (table1) and can be reduced from 4.3 to 1.1 percent in the milk of thirsty camels (Haddadin et al., 2008, Konuspayeva et al., 2009). But, a recent study reported as camel milk contains only $2 \%$ fat which are mainly composed of polyunsaturated fatty acids and omega fats (Gul et al., 2015).

Mansson (2008) claims that fat globules with the biggest average diameter are found in buffalo milk $(8.7 \mu \mathrm{m})$, the smallest in camel $(2.99 \mu \mathrm{m})$ and goat milk $(3.19 \mu \mathrm{m})$. A high state of dispersion of milk fat has a positive influence on the access that lipolytic enzymes have to small fat globules (SFGs). Therefore, milk from goats or camels is more digestible for humans (D’Urso et al., 2008). The lipid 
fraction in camel milk is characterized by a high proportion of long chain fatty acids, which accounts for 96.4 percent compared to 85.3 percent in bovine milk (Abbas, et al., 2013).

It is reported that the cholesterol level of fat of camel milk (34.5 mg.100 g-1) is higher as compared to cholesterol level (25.63 mg.100 g-1) of bovine milk fat (Konuspayeva et al., 2008). Milk fat of dromedary camels carries a lower level of carotene and lesser concentrations of short chain fatty acids as compared to milk of bovine (Stahl et al., 2006)

Cholesterol is present in the milk fat globule membrane (MFGM) and it accounts for $95 \%$ of the sterols of milk fat. SFGs are characterized by a larger surface area of MFGM per fat unit. Therefore, a bigger share of SFGs is connected with a relatively higher concentration of cholesterol in milk. Camel milk, which has the highest state of dispersion of milk fat, contains the most (of the studied animals species) cholesterol (31.3 to $37.1 \mathrm{mg} / 100 \mathrm{~g}$ milk). Camel milk is also unique concerning its fatty acid profile. It contains 6 to 8 times less of the short chain fatty acids compared to milk from cows, goats, sheep, and buffalo (Gizachew et al., 2014).Various fatty acids such as butyric, caproic, caprylic, capric, lauric, myristic, myristoleic, palmitic, palmitoleic, stearic, oleic, linoleic and arachidic acids are present in camel milk (Panwar et al. 2015).

\subsubsection{Carbohydrate}

The major carbohydrate fraction in camel milk is lactose sugar whith range between 3.3 to 5.80 percent (table 1). The nature of vegetation eaten by the camels in desert areas could be a significant factor for extensive variation in lactose contents. Camels generally like to take halophilic plants like Salosa, Acacia and Artiplex to fulfill their physiological necessities of salts. However, in some dromedary varieties of the world lactose contents found to be changed slightly over a period of time (Abas et al., 2013). Lactose readily digested by human lactase with no signs of "lactose intolerance".

\subsubsection{Minerals}

The total amount mineral dromedary camel milk is between 0.60 to 1.0 percent (Konuspayeva et al., 2009). There are significant fluctuations in minerals level due to the differences in feeding, breed,water intake (Haddadin et al., 2008) Camel milk is rich source of various minerals like Na, K, $\mathrm{Ca}, \mathrm{P} \mathrm{Mg} \mathrm{Fe}, \mathrm{Zn}, \mathrm{Cu}$ are present in camel milk (Onjoro et al., 2003). The mean values for zinc, manganese, magnesium, iron, sodium, potassium and calcium in mineral contents of dromedary camel milk (100g-1) are $0.53,0.05,10.5,0.29,59,156$ and $114 \mathrm{mg}$ respectively(Abas et al.,2013).

\subsubsection{Vitamins and Electrolytes}

Numerous vitamins such as D, E, A, C and vitamins of B group are found in dromedary camel milk (Haddadin et al., 2008; Stahl et al., 2006). Camel milk rich in vitamin C is. It was revealed that camel milk contained three to five times more vitamin $\mathrm{C}$ as compare to bovine milk. The mean value of vitamin $\mathrm{C}$ concentration present in camel milk is $34.16 \mathrm{mg} . \mathrm{L}-1$. It was reported that camel milk contains higher concentration of niacin (B3) as compared to bovine milk. According to USDA (2009), milk $(250 \mathrm{~mL})$ of dromedary camel nourish a normal adult by means of 10.5 percent of ascorbic acid (C), 5.25 percent of vitamin A, 8.25 percent of riboflavin (B2), 15.5 percent of cobalaminand pyridoxine and thiamin of the Recommended Daily Intake (RDI). In comparison, bovine milk $(250 \mathrm{~mL})$ nourish a normal adult by means of 9 percent of vitamin A, 3.5 percent of ascorbic acid (C), 11.5 percent of pyridoxine (B6), 36 percent of riboflavin (B2) and 43.5

The low $\mathrm{pH}$ due to higher concentration of vitamin $\mathrm{C}$, stabilizes the milk and therefore it can be kept for relatively longer periods without cream layer formation. The availability of relatively higher amount of vitamin $\mathrm{C}$ in camel milk is of significant relevance from the nutritional point of view as it exerts powerful anti-oxidant activity (Mal et al., 2007).

vitamin $\mathrm{C}$ and important electrolytes like calcium and iron are need for duodenal acid for calcium absorption in cases of osteoporosis is satisfied by camel milk rapidly passing the stomach, with the acid that is constantly being secreted and the vitamin $\mathrm{C}$ (ascorbic acid) increasing the amount of calcium absorbed and deposited in the bones(Levy A et al., 2013).

\subsection{Medicinal Values of Camel Milk}

Health benefit potentials of camel milk are obtained through a number of bioactive components in camel milk. These components were reported to exist naturally in camel milk (Agrawal et al., 2007a; El-Agamy, 2007); or derived from camel milk proteins using probiotic strains (Elayan et al., 2008; 
Quan et al., 2008).Study conducted between July, 2005 and January, 2006 in Babilie and Kebribeyahworedas, Jijiga Zone of the Somali Regional State reported that respondents (97.5 and $85 \%$ for Babilie and Kebribeyah, respectively) recognized the medicinal value of camel milk.This research indicated the medicinal value of camelmilk for a treatment of gastritis, asthmatics, stomach discomfort, HIV, hamot (kar), tuberculosis, fever, urinary problems and hepatitis(Asresie et al.,2014).Interviewed pastoralistsclaimed that camel milk is used to treat a number ofillnesses in human beings such as Jaundice, Malaria, Constipation, to clear the stomach, post-partum care of women, to detoxify snake venom and flatulence, jaundice, malaria and constipation for reason that camels browse on various plant species and active agents with therapeutic properties from these plant species are secreted into the Milk (Eyassu, 2007).

Sharma (2014) also agreed with the above scholars and Alemayehu (2001) who stated that in all camel rearing countries, the breeders are convinced that camel milk has special medicinal properties, especially for dropsy, jaundice and conditions affecting the lungs and spleen.

Camel milk have been acknowledged for a long time in different parts of the world to provide a potential treatment for a series of diseases such as dropsy, jaundice, tuberculosis, asthma, and leishmaniasis or kala-azar (Asresie et al., 2014).Also revealed that several studies have shown that milk is an important nutritional andfunctional sourceand couldprovide particular health benefits due to the presence of bioactive substances inmilk.

Camel milk is enriched with various protective proteins like lysozyme, lactoferrin,lactoperoxidase, NAGase, PGRP, IgG and IgA which exert antibacterial,antiviral, antifungal and antiparasitic activity, immunological properties, growth promotion activity and anti-tumor activity (Mona et al.,2010)According to Conesa et al., 2008; the known protective proteins, and their immunological action, in camel milk are:Lysozymes which participates in primary immune system based on targeting of structures common to invading pathogens, Immunoglobulins;give the immune protection to the body against infections,Lactoferrin; Iron-saturated lactoferrin prevents microbial growthin gut, participates in primary immune system, which is based on targeting of structures common to invading pathogens.

Camel milk contains peptides and proteins that exhibit its biological activities that have beneficial effect on many bioprocesses as digestion, absorption, growth and immunity (Omar et al., 2008). Further more; camel's milk can be stored at room temperature longer period than milk from other animals (YASSIN et al., 2015).

Currently, the value of camel milk has increased worldwide due to its high therapeutic value for human health. Studies confirmed that the composition of camel's milk is unique in terms of antioxidative factors, antibacterial, antiviral, antifungal and anti-tumor activity, hypoglycaemic, anticancer, to preventive aging, for autoimmune diseases effect(Al-Juboori et al.,2013, Sharma et al.,2014)

\subsubsection{Anti-Diabetic Properties of Camel Milk}

Diabetes mellitus is characterized by abnormally high blood glucose levels, resulting from low insulin secretion and/or increased insulin resistance (Gader et al., 2016).Diabetes mellitus type 1 caused by autoimmune destruction of insulin-producing beta cells of the pancreas or malfunction of the receptors for insulin on the cell surface.The subsequent lack of insulin leads to increased blood and urine glucose. But as camel milk contains tissue repairing proteins, the problem is cured (Gul et al., 2015).

According to Agarwal and co-researchers (2002) in India a comparison between conventionally treated juveniles diabetes with those also drinking camel milk showed that the group drinking the camel milk had significantly reduced blood sugar and reduced HbA1C levels. Because camel milk has following properties Camel milk has insulin like activity, regulatory and Immuno modulatory function on cells (Agrawal et al., 2005).

(b) Camel milk contains large concentration of insulin $150 \mathrm{U} / \mathrm{ml}$ (Gizachew et al., 2014). (c) Although human, cow and goat milk contain insulin, it is degraded and forms coagulum in the acids environment of the stomach (A.R. Mullaicharam, 2014). On contrary, the insulin of camel is contained within micelles and thus protected from digestion and proteolysis in the upper gastrointestinal tract; it is encapsulated in nanoparticles that facilitate its absorption and easy passing 
to the blood stream; it is again plausible that the antioxidant action of camel milk prevents metabolic syndrome, including hyperglycaemia, hyperlipidaemia, and insulin resistance (Gader et al., 2016).

The study conducted by India's Bikaner Diabetes Care Research Center (2005), reported the beneficial effects of camel milk consumption on type- 1 diabetes as it significantly reduced insulin doses required to maintain long-term glycemic, or blood sugar level under control. This study also demonstrated the insulin concentration in camel milk is higher as compared to cow milk. In the same way, a recent study also proved that camel milk is rich source of insulin (Grover et al., 2014). Furthermore, it is proved that camel milk can be used as an adjunct to insulin therapy as it appears to be safe and efficacious in improving long-term glycemic control and also helps in the reduction of insulin requirement in type 1 diabetic patient (Agrawal et al., 2011).

Biochemical studies have revealed the components of camel milk e.g. insulin like protein; lactoferrin and immunoglobulins are responsible for camel milk as anti-diabetic. In parallel, epidemiological surveys stating low prevalence of diabetes in communities consuming camel milk clearly indicate towards its hopeful role in maintaining hyperglycemia (Agrawal et al., 2013)

The long-term study was undertaken to assess the efficacy, safety and acceptability of camel milk as an adjunct to insulin therapy in type 1 diabetics.type 1 diabetic patients were grouped into two groups .Group I received usual care:diet, exercise and insulin and Group II received camel milk in addition to the usual care.. The results showed that, in camel milk receiving group, there was decrease in mean blood glucose, hemoglobins and insulin doses. From group receiving camel milk, insulin requirement reduced to zero.There was non-significant change in plasma insulin and anti-insulin antibodies in both groups. It may be stated that camel milk is safe and efficacious in improving long-term glycemic controlin type 1 diabetic patients(Amjad et al.,2013).

\subsubsection{Anti-Bacterial and Antiviral Properties}

Came milk contains antimicrobial enzymes (lactofferin and Lactoperoxidase) protective protein like caseins, stronger immune ststem and smaller immunoglobulins than other runinants.

Camel milk has higher concentrations of lactoferrin and lysozyme than bovine milk (Konuspayeva et al., 2005).Literature has shown that lactoferrin can act as either a bacteriostatic and/or bactericidal agent (Al-Majali et al., 2007). This difference in the activity may, in part, explain the wide range of MIC values for lactoferrin activity.As several studies revealed lactofferin has inhibitory activity on both Gram- positive and Gram-negative bacteria in vitro (Lee et al., 2004,FarnaudS et al., 2004,Nozaki A et al., 2004)

Benkerroum (2004) reported from his study on antimicrobial effects of camel milk against $E$. coli and L. monocytogenes confirmed that camel milk has a bacteriostatic effect against both pathogens tested, while the colostrum is bactericidal to E. coli and bacteriostatic to L. monocytogenes. This study also compared antimicrobial effect of raw camel milk and heated milk suggested that the raw milk is more effective. This justified the clue that heat treatment process may have destroyed, at least partially, some of the inhibitory systems present in the milk. The lysozyme is sensitive to heat and the LPS was shown to be completely inactivated when heated at $80^{\circ} \mathrm{C}$ for $40 \mathrm{~s}$ or at $76^{\circ} \mathrm{C}$ for $1 \mathrm{~min}$.

Al-Majali (2007) reported study of protective proteins of against gram negative and gram positive bacteria and rotavirus. study conducted by extracting Lysozyme, lactoferrin, lactoperoxidase immunoglobulin $\mathrm{G}$ and secretory immunoglobulin A were extracted from camel milk and the activity of these protective proteins was assayed against Lactococcuslactis subsp. cremoris, Escherichia coli, Staphylococcus aureus, Salmonella typhimurium and rotavirus. The result concluded that camel milk LP was bacteriostatic against the Gram-positive strains and bactericidal against Gram-negative cultures and immunoglobulins have little effect against bacteria but high titres of antibodies against rotavirus is find in camel milk.

Camel milk has been noted to have medicinal properties treating tuberculosis. Study conducted on the effect of camel milk on multiple drug resistance patients with tuberculosis concluded that camel milk can act as an adjuvant nutritional supplement in MDR patients (Mall et al., 2006).

Recent study done to test antimicrobial activity of camel caseins proved that it has bactericidal activity. Caseins were hydrolyzed successively by pepsin and pancreatin mainly into fragments with a molecular weight below $1 \mathrm{kDa}$. The antibacterial activity of camel milk of hydrolyzed caseins was increased when compared with that of native casein after successive hydrolysis by proteolytic enzymes. This suggests that antibacterial fragments derived from camel caseins were released (Jrad.Z et al., 2015) 
Immune system of camel is stronger than that of human and the small immunoglobulins pass from the camel milk into the human blood. As immunoglobulins are found in camel milk throughout lactation, drinking milk will provide a 'tool' for combatting autoimmune diseases by rehabilitating the immune system rather than is depression (Yagil and Reuven, 2004). Addition, another study also clarified that camel milk has antibacterial effect against pathogenicity induced by E. coli and $S$. aureus in doing trial on rats (mall et al., 2006).Moreover, camel milk has synergistic action with antibiotics which may be used to reduce the dose of antibiotics and decrease bacterial antibiotic resistance. Camel milk supplementation decreased the oxidative stress and normalized antioxidants biomarkers that were ameliorated by E. coli and S. aureusinjection (YASSIN et al., 2015)

\subsubsection{Camel Milk for Treatment of Crohn's Disease}

Crohn's disease is a condition that causes inflammation of the digestive system or guts that boosts with autoimmune disease. It has been approved that infection by Mycobacterium avium - subspecies: paratuberculosis (MAP) lead to a secondary autoimmune response, paving the way for Crohn's disease (Ahmed et al., 2007). Camel milk has been identified as assisting in the recovery processes of autoimmune diseases. It becomes apparent, that the powerful bactericide properties of camel milk, combined with PGRP have a quick and positive effect on the healing process (Ahmed et al., 2007).

Camel milk has powerful bactericidal properties and can rehabilitate the immune system. It was observed that drinking non-pasteurised camel milk is beneficial to people with all the variety of symptoms associated with an infection of the alimentary canal (Shabo et al. 2008) Shabo and coworkers reported that camel milk has shown good effect for treating Crohn's diseases. As the bacteria belongs to the family of tuberculosis and as camel milk has been used to treat tuberculosis it becomes apparent that the powerful bactericide properties of camel milk combined with PGRP have a quick and positive effect on the healing process. In addition, immunoglobulin's restore the immune system. (Yadav et al., 2015)

\subsubsection{Camel Milk for Treatment Autism}

Autism disease is general terms for a group of complex disorders of brain development.The etiology of many autistic cases is based primary on autoimmune disease, affecting an intestinal enzyme responsible for the formation of amino acids from the milk protein casein. Some times casein break down to power ful opioid, casomorphine instead of primarily beta-casein and betalactoglobulin. This opioid leads to typical cognitive and behavior symptoms due to brain damage (Al-Juboori et al., 2013).

The most prominent cerebral symptoms are caused by a malfunction in the formation of amino acids from two caseins in cow milk, beta-casein and beta-lactoglobulin Instead, a powerful opioid, casomorphine, is formed (Yagil and Reuven, 2013). This opioid elicits the cerebral symptoms of the autism syndrome.

But Camel milk does not contain the two caseins that form casomorphine from cow milk, so symptoms do not develop (Reichelt KI, 2003). In addition, camel milk contains protective proteins, including Igs necessary for initiating the immune system and nutritional advantages for brain development (Al-Juboori et al., 2013). Furthermore, camel milk has emerged to have potential therapeutic effects in autism. (Sharma and singh, 2014)

The consumption of camel milk in children suffering from autism showed reduction in autism symptoms and improved motor skills, language, cognition, joint coordination and skin health (Grover et al., 2015). V. Popov (2013) also reported that children drinking camel milk have had amazing improvements in their behavior and diets.

Study evaluated the effect of camel milk consumption on oxidative stress biomarkers in autistic children, by measuring the plasma levels of glutathione, superoxide dismutase, and myeloperoxidase before and 2 weeks after camel milk consumption, using the ELISA technique. All measured parameters exhibited significant increase after camel milk consumption. These findings suggest that camel milk could play an important role in decreasing oxidative stress by alteration of antioxidant enzymes and non enzymatic antioxidant molecules levels, as well as the improvement of autistic behaviour as demonstrated by the improved CARS(Laila and Nadra, 2013). 


\subsubsection{Treatment for Allergies}

The milk protein called $\beta$-lactoglobulin present in cow and mare milk is responsible for allergies in humans. However, camel milk lacks this protein and thus do not cause problem of allergies in sensitive individual. $\beta$-casein present in cow milk also causes hypersensitivity into humans. Beside, camel milk contains $\beta$ - casein, but its structure is very different from the cow milk protein. Phylogenetic differences could be responsible for the failed recognition of camels' proteins by circulating IgEs and monoclonal antibodies. Children with severe food allergies improved rapidly with camel milk. It appears that camel milk has a positive effect in children with severe food allergies (Gizachew et al., 2015) According to El-Agamy et al., (2009) absence of immunological similarity between camel and cow milk proteins may be taken an important criterion from clinical point of view. Therefore, camel milk may be suggested as a new protein source for nutrition for children allergic to cow's milk.

A person allergic to cow milk will develop an allergic reaction after ingesting buffalo, goat, sheep and horse milk proteins due to the presence of positive immunological cross-reaction with their counterparts in cow milk but researchers confirmed that camel milk does not contain the allergens which are present in ruminant milk (El-Agamy et al., 2009). So, camel milk is recognised as a good substitute for human milk as it does not contain $\beta$-lactoglobulin, a typical milk protein characteristic of ruminant milk (Shabo et al., 2005).

Another fact is that the components of camel milk include immunoglobulins similar to those in mothers' milk, which reduce children's allergic reactions and strengthen their future response to foods. It appears that camel milk has a positive effect in children with severe food allergies. The reactions are rapid and long lasting. (Shabo et al., 2005)

Camel's milk can used as an option for the individuals intolerant to lactose of cow's milk (de Almeida et al.,2011) Camel milk contained low lactose of small molecules and easily digests and metabolized by the human body (Ehlayel et al.,2011). Individuals intolerant to lactose are able to accept camel milk without adverse symptoms (Yosef et al., 2005).

\subsubsection{Anti-Diarrheal Properties of Camel Milk}

Camel's milk contains a number of 'protective proteins' like lactoferrin, lactoperoxidase, NAGase and PGRP that exert immunologic, bacteriocidal and viricidal properties. Among the "protective proteins" in camel milk lysozyme, lactoferrin, LP and PRP (Yagil and Reuven, 2013) have antidiarrheal/antibacterial action as well as high titers of antibodies against rotavirus, and they impact on the immune system. It should be noted that rotavirus is the most common cause of diarrhea inchildren under 5 years old (Greenberg and Estes, 2009). Since camel milk is rich in anti-rotavirus antibodies the diarrhea subsides.

\subsubsection{Therapuetic Effects of Camel Milk on Cancer, Tumor and Ulcer}

It has been comfirmed that lactoferrin has ability to inhibit the proliferation of cancer cell in vitro, and repair of DNA damage (Hosam et al., 2013). The main iron binding protein of camel milk, lactoferrin is potent for 56\% reduction of cancer growth (Habib et al., 2013). Korashy and co-researchers (2012) investigated the molecular mechanisms that govern the effect of camel milk on human cancer cells demonstrated that camel milk induces apoptosis in HepG2 and MCF7 through apoptotic and oxidative-stress-mediated mechanisms. Other scholars also added that camel milk has antigenotoxic and anticytotoxic effects through inhibition of MnPCEs and improves the mitotic index of bone marrow cells (Salwa et al., 2010). More recent literature claims that in a series of in vitro experiments, Dr Fatin Khorshid succeeded in demonstrating as camel milk can stop the growth of tumour cells and malignant cells such as hepatocellular carcinoma, colon carcinoma, human glioma cells, lung cancer cells and leukaemic cells (Gader et al., 2016). Dr Fatin Khorshid also suggested that this anti-cancer action could be both a direct cell cytotoxicity and anti-angiogenic action (cutting blood supply to tumur cell) of camel milk lactoferin.

There are a number of tumors which can be cured with camel milk; very active antibodies bind onto the tumors, killing the tumor cells with out damaging healthy tissue. But human antibodies are too big to do this (Levy et al., 2013). It is also revealed that anti-tumor properties of camel milk are due to strong antimicrobial and anti-oxidative activities that help in reduction of liver inflammation and camel milk is rich with nutrients that are required for healthy liver function. Conversely, camel milk 
also shown to have potential thrombolytic action, as it causes inhibition of coagulation and fibrin formation which in turn hinders the spread and growth of metastatic tumour cells (Abdelgadir et al., 2013).

Camel milk has been proved to have pronounced antiulcer properties. Nonetheless, it contains high levels of vitamins $\mathrm{C}, \mathrm{A}, \mathrm{B} 2$ and $\mathrm{E}$ (acidic $\mathrm{pH}$ ) and is very rich in magnesium and zinc (Al-wabel and Naser, 2012). These vitamins are useful in reducing the oxidative stress caused by toxic agent and Magnesium is very essential for absorption and metabolism of vitamins, B, C and E (Traber and Stevens, 2011). Additionally, magnesium is esential for biosynthesis of glutathione; prevents damage to cellular components caused by free radicals, peroxides, heavy metals. More recently, magnesium significantly enhances the antioxidant defence (Markiewicz et al., 2011).

A protective effect of zinc has been reported against the cellular toxicity due to palliative effect on oxidative stress and apoptosis, activation of the antioxidant system to decreased lipid peroxides (Jihen et al., 2011). Moreover, camel milk can generate nitric oxide it stimulates mucus production, inhibits the adherence of neutrophiles to the endothelial cells and, especially, increases the blood flow to the gastric mucous membrane (Al-wabel and Naser A., 2012).

\subsubsection{Camel Milk Effect as Antiaging}

Salami and co-workers (2011) studied the effect of camel milk as anti-aging and suggested that when camel milk is consumed and digested, the produced peptides start to act as natural antioxidants and ACE-inhibitors.Camel milk is good for anti-ageing as the high levels of vitamin $\mathrm{C}$ protect collagen.Vitamin $\mathrm{C}$ in camel milk has antioxidant and tissue repair protection activities. Vitamin $\mathrm{C}$ is an essential water soluble vitamin that helps protect the immune system. According to Natural Standard Research, Vitamin C is necessary in the body for the production of collagen, a protein that aids in the growth of cells and blood vessels and gives skin its firmness and strength. Collagen is found in the skin, joints and cartilage; by increasing the production of collagen. Vitamin $\mathrm{C}$ strengthens the structural support and resiliency of skin so helps repair. Vitamin $C$ is an antioxidant that slows the rate of free-radical damage which causes skin dryness, and wrinkles (Escott-Stump, 2008) Vitamin C can literally reverse skin aging.

Camel milk has anti aging effect due to presence of $\alpha$-hydroxyl acids which are known to plump the skin and smoothies fine lines. Alpha- hydroxyl acids help to shed the outer horny layer of dead cells on the skin (epidermis) by helping to break down sugars, which are used to hold skin cells together. This helps in revealing new cells, which are more elastic and clear. Alpha-hydroxyl acids helps to eliminate wrinkles and age spots and relieve dryness as they make the outer layer of the skin thinner and support the lower layer of the dermis by making it thick. In addition, liposome occurring in camel milk is applicable for a potential cosmetic ingredient to improve anti-aging effect (Choi et al., 2013).

\subsubsection{Therapuetic Effect Camel Milk on Hepatitis}

Scientific publications have shown that camel milk cures both hepatitis B and hepatitis C. The special fat in camel milk soothes the liver and has beneficial action on chronic liver patients (Saltanat $\mathrm{H}$, 2009). There is also a possibility that the relatively high concentrations of ascorbic acid in camel milk helps in improving liver function (Gul et al., 2015). But Subsequent studies have shown that camel lactoferrin markedly inhibits hepatitis $C$ virus genotype 4 infection through preventing the entry of the virus into the cells (Gader, 2016). Additionally, camel lactoferrin is more potent anti-viral agent than bovine and human lactoferrins, even its anti-parasitic action can clear Schistosoma Mansoni-(Redwan et al., 2007, Maghraby et al., 2005).

\subsubsection{Camel Milk for Treatment of Arthritis}

Camel milk has higher amount of iron chelating protein known as lactoferrin. This protein removes free iron from joints of arthritic patients thereby improves arthritic. (Panwar et al., 2015)

\subsubsection{Skin Disease Treatment and Cosmetic Values of Camel Milk}

Researchers say that the ingredient's vitamin B, C carotin and iron content have crucial for skin. The milk contains lanolin and other moisturizing properties providing a calming and soothing effect on the skin. In addition to keeping the skin beautiful used to treat skin disorders such as dermatitis, Acne, Psoriasis and Eczema. More over, camel milk is natural source of alpha-hydroxy acids for softening the skin, keeping it supple, smooth and preventing wrinkles. http://www.camelproductsaustralia.com/ \#!benefits-of-camel-milk/cmu9). 


\section{CONCLUSION AND RECOMMENDATION}

Camel is a vital animal to daily life of desert dwellers as a source of food and a means of transportation, and just as importantly, its milk uses as medicines for diverse ailments. Camels produce more milk and for longer period of time than any other milk animal held under the same harsh condition. Camel milk so called white gold of the desert is more similar to human milk than any other milk. Camel milk is unique containing various protective proteins like lysozyme, lactoferrin, lactoperoxidase, immunoglobulins which exert antioxidatives, antibacterial, antiviral, antifungal, hypoglycaemic, antiparasitic, growth promotion, aging prevention, autoimmune diseases and antitumor activity.

Camel milk contains high levels of insulin or insulin like protein which pass through the stomach without being destroyed. Camel's milk cures severe food allergies, skin diseseses and hepatitis. Although camel milk has such values, it's less appreciated thus its consumption is restricted to pastoral area.

Based on the above outline the following recommendations are forwarded:

$>$ Further studies should be conducted on the chemical composition and medicinal value of camel milk.

Camel milk should be given to the people with lactose intolerance and to diabetic patients as adjunctive with insulin therapy.

$>$ Camel should incorporated in to diary sector

$>$ Training on camel in general and the chemical composition and medicinal value of camel milk in particular should be integrated in the livestock extension program

Ethiopia which has the highest potential of camel population should give priority to further investigate the medicinal value of the animal.

\section{ACKNOWLEDGEMENT}

First and foremost I would like praise God, the almighty, the author of knowledge and wisdom, for providing me this opportunity and granting me the capability of proceding successfully. I would extend my deepest gratitude to Jimma university club of Oromo History, Culture and Language Development,"Gumii Dagaagina Aadaa,Seenaa fi Afaan Oromoo,GDASAO" for offering me computer service for reality of this work. Most importantly, none of this would have been possible without the love and patience of my family. They have been a constant source of love, concern, support and strength all these years. I would like to express my heart-felt gratitude to them.

\section{REFERENCES}

Abbas,S.,Hifsa,A.,Aalia,N., \&Lubna, S. (2013). Physico-chemical analysis and composition of camel milk. International Research, 2(2), 85-98.Adlerova,L.,Bartoskova1, A. and Faldyna, M. Lactoferrin: a review.VeterinarniMedicina, 53, (9): 457-468, 2008.

Agrawal et al., 2003R.P. Agrawal, S.C. Swami, R. Beniwal, D.K. Kochar, M.S. Sahani, F.C. Tuteja, S.K. GhouriEffect of camel milk on glycemic control, risk factors and diabetes quality of life in type-1 diabetes: a randomised prospective controlled studyJournal of Camel Practice and Research, 10 (2003), pp. 45-50.

Agrawal, R. P., et al. "Camel milk: a possible boon for type 1 diabetic patients." Cellular and molecular biology 59.1 (2013): 99-107.

Agrawal,R.,Jain,S.,Shah,S.,Chopra, A.and Agrawal, V.Effect of camel milk on glycemic control and insulin requirement in patients with type 1diabetes: 2- years randomized controlled trial. European Journal of ClinicalNutrition 65, 1048-1052, September, 2011.

Ahmed, Isam A. Mohamed, Efadil E. Babiker, and Eshraga A. Eissa. "Physicochemical, Microbiological And Sensory Characteristics Of Yoghurt Produced From Camel Milk During Storage." (2015).

Ahmed, M. The etiology of mycobacterium aviumsubspeciesparatuberculosis in Crohn's disease.Saudi Med. J.Vol.28 (10), 1479-1484, 2007.

Al Kanhal, Hamad A. "Compositional, technological and nutritional aspects of dromedary camel milk." International Dairy Journal 20.12 (2010): 811-821. 
Al-Juboori, A. T., et al. Nutritional and medicinal value of camel (Camelusdrome milk."Second International Conference on Food and Environment: The Quest for a Sustainable Future, Budapest, Hungary, 22-24 April, 2013..WIT Press, 2013.

Al-Juboori, A. T., Mohammed, M., Rashid, J., Kurian, J., El-Refaey, S., Brebbia, C. A., \& Popov, V. (2013). Nutritional and medicinal value of camel (Camelusdromedarius) milk. In Second International Conference on Food and Environment: The Quest for a Sustainable Future, Budapest, Hungary, 22-24 April, 2013. (pp. 221-232).

Almeida, Roberto R. Camel milk : Characteristics and perspectives for use in clinical practice. Rev ChilNutr Vol. 38, N², June 2011, pp. 211-218, 2011.

Al-wabel, Naser A., et al. "Antiulcerogenic effect of camel milk against ethanol induced gastric ulcers in rats." (2012).

Amany, S., Mahmoud, A. and Ahmed, M. Anti-schistosomal activity of colostral and mature camel milk on Schistosomamansoni infected mice. Asia Pac J ClinNutr. 14 (4):432-438, 2005.

Amjad, A. and Mohammad, A. Hepatoprotective Effects of Camel Milk against CCl4-induced Hepatotoxicity in Rats.Asian Journal of Biochemistry. Vol. 6, Issue: 2, page: 171-180,2011.

Asresie, Aleme, and Mohammed Yusuf. "Traditional Consumption, Therapeutic Value and Its Derived Dairy Products of Dromedary Camel (Camelus Dromedaries) Milk in Somali Regional State, Eastern Ethiopia: A Review." Global Journal of Animal Scientific Research 3.1 (2014): 240-246.

Barłowska, J., Litwi, C., Kedzierska-Matysek, M. and Litwi, C. (2007): Non Polymorphism of caprine milk as1-casein in relation to performance of four polish goat breeds. Pol J Vet Sci,10:159-64.

Beermann, Christopher, and Julia Hartung."Physiological properties of milk ingredients released by fermentation."Food \& function 4.2 (2013): 185-199.

Benkerroum, Noreddine, et al. "Antimicrobial activity of camel's milk against pathogenic strains of Escherichia coli and Listeria monocytogenes." International journal of dairy technology 57.1 (2004): 39-43.

Conesa. C., Sánchez, L., Rota, C., Pérez, M., Calvo, M. and Farnaud, S.Isolation of lactoferrin from milk of different species: Calorimetric and antimicrobial studies. Comp BiochemPhysiol; 150:131-9, 2008.

D’Urso, S.,Cutrignelli, M., Calabr,' S., Bovera, F., Tudisco, R., Piccolo, V. and oInfascelli, F. (2008): Influence of pasture on fatty acid profile of goat milk. J AnimPhysiolAnimNutr, 92:405-10.

Ehlayel, M., Hazeima, K., Al-Mesaifri, F. and Bener, A. Camel milk: an alternative for cow's milk allergy in children. Allergy Asthma Proc. May-Jun; 32(3):255-8, 2011.

El Sayed, I., et al. "Antibacterial and antiviral activity of camel milk protective proteins."Journal of Dairy Research 59.02 (1992): 169-175.

El-Agamy, E. I., M. Nawar, S. M. Shamsia, S. Awad and G. F. W. Haenlein. (2009). Are camel milk proteins convenient to the nutrition of cow milk allergic children. SmallRum. Re82: 1-6

El-Hatmi, H., Girardet, J. and Attia, H. (2007): Characterization of whey proteins of camel (Camelusdromedarius) milk and colostrum. Small Rumin Res, 70:267-71.

FAO (2013).Statistical year book.Food and Agriculture Organization of the United Nations, Rome, Italy, 2013.

Gader, Abdel Galil M. Abdel, and Abdulqader A. Alhaider. "The unique medicinal properties of camel products: A review of the scientific evidence." Journal of Taibah University Medical Sciences (2016).

Gizachew, Ayele, Jabir Teha, TadesseBirhanu,(2015), Ethiopia Nekemte. "Review on Medicinal and Nutritional Values of Camel Milk."

Greenberg HB, Estes MK. Rotaviruses: from pathogenesis to vaccination. Gastroenterology 2009; 136: $1939-51$.

Gul, W., Farooq N., Anees D., Khan U., Rehan F. "Camel Milk: A Boon to $\quad$ Mankind." International Journal of Research Studies in Biosciences (IJRSB) 3.11(2015): 23-29

Guo, H., Pang, K., Zhang, X., Zhao, L., Dong M. and Ren, F.( 2007):Composition, physicochemical properties, nitrogen fraction distribution, and amino acid profile of camel milk. $J$ Dairy Sci,90:1635-1643. 
H.M. Hosam, I.H. Wissam, R. Schneider-Stock, H.M. Hassan, Camel milk lactoferrin reduces the proliferation of colorectal cancer cells and exerts antioxidant and DNA damage inhibitory activities, Food Chemistry 141 (2013) 148-152.Haddadin, M. S. Y., S. I. Gammoh and R. K. Robinson. (Haddadin, Malik SY, Sana I. Gammoh, and Richard K. Robinson. "Seasonal variations in the chemical composition of camel milk in Jordan." Journal of Dairy Research 75.01 (2008): 8-12.

http://www.camelproductsaustralia.com/\#!benefits-of-camel-milk/cmu9).

Jrad, Z., et al. "Antimicrobial activity of camel milk casein and its hydrolysates."ActaAlimentaria 44.4 (2015): 609-616.

Kappeler, S., Z. Farah and Z. Puhan. (2005). 50-Flanking regions of camel milk genes are highly similar to homologue regions of other species and can be divided into two distinct groups. J. Dairy Sci. 86: 498-508

Karray et al., 2005N. Karray, C. Lopez, M. Ollivon, H. AttiaLa matièregrasse du lait de dromadaire: composition, microstructure et polymorphisme. Une revueOCL, 12 (2005), pp.439-446

Khaskheli, M., M. A. Arain, S. Chaudhry, A. H. Soomro and T. A. Qureshi (2005). Physico chemical quality of camel milk. J. Agri. Soci. Sci. 2: 164-166.

Konuspayeva et al., 2008G. Konuspayeva, E. Lemarie, B. Faye, G. Loiseau, D. MontetFatty acid and cholesterol composition of camel's (Camelusbactrianus, Camelusdromedarius and hybrids) milk in KazakhstanDairy Science and Technology, 88 (2008), pp. 327-340

Konuspayeva, G., B. Faye, and G. Loiseau. "The composition of camel milk: a meta- analysis of the literature data." Journal of Food Composition and Analysis 22.2 (2009): 95-101.

Konuspayeva, G., Serikbayeva, A., Loiseau, G., Narmuratova, M. and Faye, B. Lactoferrin of Camel Milk of Kazakhstan. NATO Series, I: Life and behavioural Science. Vol. 362, 158-167, 2005.

Korashy, H., El Gendy, M., Alhaider, A. and El-Kadi, A. Camel milk modulates the expression of aryl hydrocarbon receptor-regulated genes,Cyp1a1, Nqo1, and Gsta1, in murine hepatomaHepa 1c1c7 cells. J Biomed Biotechnol.782 642,2012.

Levy, Avi, Lillian Steiner, and ReuvenYagil. "Camel milk: disease control and dietary $\quad$ laws." Journal of Health Science 1.1 (2013): 48-53.

Maghraby, Amany S., Mahmoud A. Mohamed, and Ahmed M. Abdel-Salam. "Anti-schistosomal activity of colostral and mature camel milk on Schistosoma mansoni infected mice." Asia Pacific journal of clinical nutrition 14.4 (2005): 432.

Magjeed, 2005 N.A. MagjeedCorrective effect of milk camel on some cancer biomarkers in blood of rats intoxicated with aflatoxin B1Journal of the Saudi Chemical society, 9 (2) (2005), pp. $253-263$

Mal et al., 2006G. Mal, D.S. Sena, V.K. Jain, M.S. SahaniTherapeutic value of camel milk as a nutritional supplement for multiple drug resistant (MDR) tuberculosis patients Israel Journal of Veterinary Medicine, 61 (2006), pp. 88-91

Mal, G., et al. "Therapeutic value of camel milk as a nutritional supplement for multiple drug resistant (MDR) tuberculosis patients." Israel Journal of Veterinary Medicine 61.3/4 (2006): 88.

Mal, G., Suchitra, D., Jain, V. and Sahani, M. Therapeutic value of camelmilk as nutritional supplement for multiple drug resistant (MDR) tuberculosis patients. Vol. 61 - No. 3-4, 2006.

Mal, G., Suchitra, S. D. and Sahani, M. S. 2007. Changes in chemical and macro-minerals content of dromedary milk during lactation. Journal of Camel Practice and Research, 14(2): 195197.Malik, Ajamaluddin, et al. "A study of the anti-diabetic agents of camel milk." International journal of molecular medicine 30.3 (2012): 585-592.

Mansson, H. (2008): Fatty acids in bovine milk fat. Food Nutr Res,52.DOI: 10.3402/fnr.v52i0.1821.

Markiewicz-Górka, Iwona, et al. "Influence of selenium and/or magnesium on alleviation alcohol induced oxidative stress in rats, normalization function of liver and changes in serum lipid parameters." Human \& experimental toxicology (2011): 0960327111401049.

Mohamad, R., Zekry, Z. Al-Mehdar, H., Salama, O., El-Shaieb, S., El-Basmy, A., Al- Said,M. and Sharawy, S.Camel milk as an adjuvant therapyfor the treatment of type 1 diabetes: verification of a traditional ethnomedical practice. J Med Food. Apr;12(2):461-5, 2009. 
Mona, E., Ragia, O., Abeer, A. and Mosa, T. Biochemical Effects of Fermented Camel Milk on Diarrhea in Rats. New York Science Journal; 3(5), 2010.

Mullaicharam, World J Pharm Sci 2014; 2(3): 237-242 11. http://www. FAO.Org/ DOCREP/ 003/ X6528/ EX6528E00.Htm. 12. Christie, W.W and Clapperton, J.L. Structures of the triglycerides of cow's milk, fortified milk (including infant formula) and human milk. J. Soc. Dairy

Omar, R.H., Eltinay, A.H," Microbial quality of camel's raw milk in central southern region of united Arab Emirates," Emir J Food Agric., 20 (1): 76-83. 2008.

Onjoro, P., Schwartz, H. J., Njoka, E. N. and Ottaro, J. M. 2003. Effects of mineral status in the soil, forage, water, blood, milk, urine and faeces on milk production of lactating, free ranging camels in Northern Kenya. Proc. DeutscherTropentag, 8-10.

Panwar, Rohit, et al. "Camel milk: Natural medicine-Boon to dairy industry."(2015)

Redwan, EL-Rashdy M., and Ashraf Tabll. "Camel lactoferrin markedly inhibits hepatitis C virus genotype 4 infection of human peripheral blood leukocytes." Journal of immunoassay \& immunochemistry 28.3 (2007): 267-277.

Reichelt KI, KnivsbergAM. Can pathophysiology of autism be explained by the nature of the discovered urine peptides? NutrNeurosci2003;6: 19-28.

Sabahelkhier, M. K., M. M. Faten, and F. I. Omer. "Comparative Determination of Biochemical Constituents between Animals (Goat, Sheep, Cow and Camel) Milk with Human Milk." Research Journal of Recent Sciences 1.5 (2012): 69-71.

Salami, Maryam, et al. "Biological activity of camel milk casein following enzymatic digestion."Journal of dairy research 78.04 (2011): 471-478.

Saltanat H (2009). The influences of camel milk on the immune response of chronic hepatitis B patients, Chinese J. Cellular Mol. Immunol; 25: 431-433. Grant, David, et al. "SoyBase, the USDA-ARS soybean genetics and genomics database." Nucleic acids research (2009): gkp798.

Shabo, Y., Barzel, R., Margoulis, M. and Yagil, R. Camel milk for foodallergies in children. Israel Med Assoc J 2005; 7:796-8, 2005.

Shabo, Y., R. Barzel, and R. Yagil."Etiology of Crohn's disease and camel milk treatment."Journal of Camel Practice and Research 15.1 (2008): 55-59.

Shamsia, S. M. "Nutritional and therapeutic properties of camel and human milks."International Journal of Genetics and Molecular Biology 1.2 (2009): 052-058.

Sharma, Chakrapany, and Chandan Singh."Therapeutic Value of Camel Milk-A Review."Advanced Journal of Pharmacie and Life science Research 2.3 (2014): 7-13.

Simeneh, K. (2015). CHARACTERIZATION OF Camelusdromedarius IN ETHIOPIA: PRODUCTION SYSTEMS, REPRODUCTIVE PERFORMANCES AND INFERTILITY PROBLEMS (Doctoral dissertation).

Traber, Maret G., and Jan F. Stevens. "Vitamins C and E: beneficial effects from a mechanistic perspective." Free Radical Biology and Medicine 51.5 (2011): 1000-1013.

WIT Press.Al-Majali, Ahmad M., et al. "Lactoferrin concentration in milk from camels (Camelusdromedarius) with and without subclinical mastitis." International Journal of Applied Research in Veterinary Medicine 5.3 (2007): 120.

Yadav, Alok Kumar, et al. "Composition and medicinal properties of camel milk: A Review." Asian Journal of Dairy and Food Research 34.2 (2015): 83-91.

Yagil, Reuven. "Camel milk and autoimmune diseases: historical medicine." (2004).

Yagil, Reuven. "Camel milk and its unique anti-diarrheal properties."The Israel Medical Association Journal 15 (2013): 35-36.

YASSIN, Magdy Hassan, et al. "Antimicrobial Effects of Camel Milk against Some Bacterial Pathogens." Journal of Food and Nutrition Research 3.3 (2015): 162-168.

Yosef, S., Reuben, B., Mark, M. and Reuven, Y. Camel Milk for Food Allergies in Children. IMAJ Vol 7 December, 2005.

Zibaee, Said. "Nutritional and Therapeutic Characteristics of Camel Milk in Children: A Systematic Review." Electronic physician 7.7 (2015): 1523.

Zicarelli, L. (2004): Buffalo milk: its properties, dairy yield and mozzarella production. Vet Res Commun, 28:127-35. 